\title{
O CIBERPLÁGIO COMO FENÓMENO EMERGENTE NO ENSINO SECUNDÁRIO
}

\author{
Manuel Meirinhos ${ }^{1}$ \\ Ana Valadar \\ Instituto Politécnico de Bragança - Escola Superior de Educação. Bragança, Portugal.
}

\begin{abstract}
Resumo. Com este estudo pretendemos tecer uma abordagem ao fenómeno do plágio, mais concretamente à sua vertente em emergência, que é o ciberplágio. $\mathrm{O}$ fenómeno está relacionado com a emergência da utilização da internet nos processos de aprendizagem escolar. Com base na metodologia de estudos de caso descritivo foi investigada a comunidade escolar correspondente ao Ensino Secundário, de uma escola do Norte de Portugal, a fim de tentar compreender o comportamento em relação a essa prática. Verificamos que, em relação à situação estudada, a maioria dos alunos tem conhecimentos sobre o plágio e grande parte pratica-o com maior ou menor frequência. Parecem recorrer a esse comportamento por falta de informação (sobre a temática e sobre as regras para uso de trabalhos) e por uma questão de falta de gestão do tempo na realização dos trabalhos escolares. Identificamos formas de combater o plágio tendencialmente mais informativas do que punitivas. Procuramos tornar essa temática mais consciente, abrindo caminho a novas investigações, para que, de forma fundamentada, possam ser tomadas medidas aptas a mudar hábitos que em nada contribuem para a aprendizagem significativa dos conteúdos escolares.
\end{abstract}

Palavras-chave: plágio, ciberplágio, Ensino Secundário, internet.

\section{EL CIBERPLAGIO COMO FENÓMENO EN EMERGENCIA EN LA ENSEÑANZA SECUNDARIA}

Resumen. Con este estudio se pretende abordar el fenómeno del plagio, más específicamente a su modelo en emergencia que es ciberplagio. El fenómeno está relacionado con la emergencia del uso de Internet en los procesos de aprendizaje escolar. La investigación ha seguido la metodología de estudio de caso descriptivo y ha sido estudiada la comunidad escolar correspondiente a la educación secundaria en una escuela en el norte de Portugal, con el fin de tratar de entender el comportamiento en relación con esta práctica. Hemos encontrado que en relación a la situación estudiada, la mayoría de los estudiantes tiene conocimiento sobre el plagio y la practica con mayor o menor frecuencia. Los alumnos parecen recurrir a este comportamiento por falta de información sobre el tema y las reglas para la realización de trabajos escolares, y por una cuestión de falta de gestión del tiempo en la consecución del trabajo escolar. Las formas de combatir el plagio tienden a ser más informativa que punitiva. Buscamos hacer este tema más consciente para la comunidad educativa, abriendo el camino a nuevas investigaciones, para que de forma razonable se puedan tomar medidas que cambien hábitos que en nada contribuyen para el aprendizaje significativo de los contenidos escolares.

\footnotetext{
${ }^{1}$ Manuel Meirinhos: Instituto Politécnico de Bragança, Escola Superior de Educação, Campus de Santa Apolónia - 5300-253. Bragança. Portugal. meirinhos@ipb.pt.
} 
Palabras clave: plagio, ciberplagio, Enseñanza secundaria, internet.

\title{
THE CYBERPLAGIARISM AS EMERGING PHENOMENON IN SECONDARY EDUCATION
}

\begin{abstract}
With this study we intend to address the phenomenon of plagiarism, specifically in its emergence that is cyberplagiarism. The phenomenon is related to the emergence of the use of Internet in the school learning processes. Based on a descriptive case studies methodology, we studied the secondary education community in a school in northern Portugal, in order to try to understand the behavior in relation to this practice. We found that in relation to the studied situation, most students know about plagiarism and often or seldom practice it. They seem to maintain this behavior due to the lack of information (on the subject and the rules for assignments) and as a matter of the lack of time in achieving the schoolwork. Identifying ways of combatting plagiarism tend to be more informative than punitive. We seek to make this a more conscious issue, opening the way to new research, so that, with good reason, steps to change habits that do not contribute to the significant learning of the school contents can be taken.
\end{abstract}

Keywords: plagiarism, cyberplagiarism, secondary education, Internet.

\section{Introdução}

A escola, enquanto instituição ligada à informação, ao conhecimento e à educação, não pode estar alheada dos fenómenos emergentes desta nova sociedade suportada pelas tecnologias da informação e comunicação. É necessário ter consciência de que as tecnologias digitais transformaram a sociedade e os alunos desenvolveram novas formas de comunicar, de interagir e novas estratégias de aceder e difundir a informação. Esta relação dos alunos com a informação, difundida pelas redes, é nova para a escola e dela parecem emergir alguns fenómenos, entre os quais o ciberplágio académico.

A geração Net, ou também designada por geração Z (zapping), é a geração dos nativos digitais, considerada aquela que nasceu depois do advento da internet, utiliza as novas tecnologias de forma natural como fazendo parte do quotidiano da grande maioria de crianças e jovens. A imensa quantidade de informação, em formato digital, que é disponibilizada através da internet, suscita nos jovens novos hábitos de trabalho e novas formas de lidar com essa informação de fácil acesso. A facilidade de trabalhar a informação digital é diferente de trabalhar com a informação em suporte papel. Tanto professores como alunos e agentes do sistema educativo em geral deveriam estar conscientes das ocorrências que podem emergir dessa facilidade. O fenómeno do ciberplágio parece estar em emergência, mas alguns autores, no conjunto de 
denominações que procuram caracterizar esta nova geração, atribuem-lhe o rótulo de "geração copy-paste" (Comas et al., 2005).

Os estudos sobre a prática da desonestidade intelectual surgem sobretudo a nível de Ensino Superior. A preocupação parece centrar-se neste nível de ensino, enquanto no Ensino Básico tudo parece ocorrer como se nada se passasse. É neste ponto que se justifica a pertinência deste trabalho. O primeiro passo para resolver um problema é ter consciência de que ele existe. Provavelmente muitos dos alunos do Ensino Superior não iniciam nesse nível a prática de plagiar. Essa prática poderá assentar em hábitos já enraizados dos níveis de ensino anteriores e, para poder combater essa fraude a que alguns autores já denominam de praga, poderá haver necessidade de ir à raiz do problema.

Com o presente estudo de caso, pretendemos averiguar se os alunos do ensino secundário recorrem ou não à prática do plágio no seu percurso escolar. Propomos também conhecer se de facto eles têm conhecimento da ilegalidade desta prática, se o praticam, e procurar quais as causas deste comportamento e formas de o combater. Iniciaremos por uma revisão bibliográfica abordando o contexto informacional da sociedade digital, para depois nos dirigirmos mais concretamente para a problemática do plágio e na sua vertente em emergência o ciberplágio. Tentaremos justificar a pertinência de um estudo desta natureza, pois apesar de a temática estar bastante estudada a nível do Ensino Superior e pouco ou nada a níveis de ensino inferiores, não significa que estes estejam imunes.

Destaca-se que a internet veio provocar uma verdadeira revolução no mundo da informação e do conhecimento. As páginas pessoais, os blogs, as wikis e as redes sociais criaram a infraestrutura necessária para os jovens passarem a dispor de um meio que lhes permite a expressão fácil e a colocação on-line de informação pouco relevante e cientificamente não validada. Os buscadores de informação, como o Google, fizeram com que qualquer aluno tenha instantaneamente uma superabundância de informação sobre qualquer tema, a partir de qualquer dispositivo móvel ligado à internet. $\mathrm{O}$ acesso à informação na era da internet é bastante diferente do acesso à informação no mundo analógico. Não foi apenas o acesso que se alterou, mas também a quantidade e a velocidade a que essa informação se produz e se disponibiliza. Na época atual, existe superabundância de informação para qualquer tema escolar, e os alunos podem não possuir competências para lidar de forma correta com esse "mar" de informação.

A grande quantidade de recursos, materiais, artigos, multimédia, livros, revistas especializadas, bases de dados, portais temáticos, etc. acessíveis através da internet - a maioria dos quais não estão acessíveis desde outro espaço ou canal , a facilidade e comodidade de acesso aos mesmos e a gratuidade da maior parte deles são sem dúvida fatores de grande ajuda para qualquer que deseje consultar informação com finalidades académicas e, de certa forma, não se concebe hoje em dia um trabalho académico, o planeamento de uma investigação, a ampliação 
de conteúdos de uma disciplina, o trabalho para uma aula, etc. Sem contar com a ajuda da internet como elemento de consulta (Comas e Sureda, 2007, s. p).

A implementação das tecnologias na educação como recursos de aprendizagem é, hoje, indiscutível na escola. Contudo, é notório o desfasamento existente entre o mundo escolar e o mundo digital que a maioria dos alunos vivencia fora da escola, relacionando-se em redes sociais e comunicando-se através do "telemóvel-computador". Entramos assim nos conceitos de "geração Net" (Tapscott, 1997) ou de "nativos digitais" (Prensky, 2001) ou de "geração Z", a geração nascida depois do advento da internet. Ao alterar-se o quadro social de referência alteram-se ou desvanecem-se também as competências, as regras com que atuamos, os valores que utilizamos e os hábitos que sustentavam o nosso modo de trabalhar. $\mathrm{O}$ acesso à informação à distância de um clique faz com que a relação com a informação seja diferente da relação existente no quadro de referência analógico anterior. Surge no novo contexto a chamada geração “copy-paste". O processo básico para a realização de um trabalho escolar é o copiar e o colar.

Muito baseados no princípio de que na internet tudo é de todos, os alunos fazem uso de forma indiscriminada do copiar-colar, isto é, copiam e colam textos sem a menor das preocupações éticas. Não escrevem, não elaboram raciocínios, simplesmente "encaixam" textos. Muitas vezes o acesso à informação, por falta de competências de lidar com ela, não passa de um acesso ao lixo informativo (informação sem interesse de blogs e sites pouco fidedignos), por ausência de competências para selecionar e validar a qualidade da informação.

Como referem Pinto e Gerrero (2014):

São navegantes em oceanos de informação que apresentam uma relação com a cultura escrita a favor da imagem, do som e do multimédia. Desconhecem o valor da informação e carecem de um referencial qualitativo para a avaliar. Não sabem delimitar as suas necessidades de informação e enfrentam com êxito uma busca avançada. Ademais ignoram os aspetos éticos/legais do uso da informação (p. 29).

A brecha digital existente entre a maioria dos alunos, que lidam com a informação em formato digital de forma natural, e dos professores, formados numa cultura mais analógica, pode não estar a contribuir para fazer emergir a consciência da problemática do ciberplágio, enraizada nos alunos como algo habitual e normal. Parecenos, portanto, deveras importante que toda a comunidade escolar se consciencialize que esta prática do plágio com recurso à internet está cada vez mais enraizada nos nossos alunos, pois fazem desta uma prática usual e comum.

Nesse ínterim, o plágio é uma prática que existe há muito tempo. É uma das formas de desonestidade académica, que inclui uma longa lista de delitos, a partir da qual os alunos pretendem obter vantagens (Underwood, 2013). Não poderemos esquecer que o próprio plágio configura várias formas, desde a cópia integral ao texto 
reescrito mantendo as mesmas ideias, mas tem sempre uma característica comum que é omitir referências e fontes (Sureda e Comas, 2011). A maior parte dos estudos feitos neste campo enquadram-se na temática do ensino superior, onde os efeitos práticos do plágio poderão ser mais visíveis e ter mais consequências, pois trata-se de pessoas adultas das quais se espera elevado desenvolvimento moral. Comas e Sureda (2007), com base na revisão científica feita a este nível sobre a prática do ciberplágio em contexto académico, salientam que a abordagem ao ciberplágio se tem feito em quatro aspetos fundamentais: i) - Análise e quantificação da prevalência, caracterização dos alunos plagiadores e extensão do fenómeno; ii) - Tipos de ciberplágio; iii) - Análise das causas associadas ao fenómeno e possíveis soluções do problema; iv) - Avaliação da precisão e utilidade do software antiplágio.

No atual estado de desenvolvimento da sociedade de informação, o plágio está cada vez mais ligado à internet. Poderemos assim falar da emergência do "ciberplágio" como uma especificidade do plágio, que consistirá:

... no uso das TIC (principalmente e os recursos a ela associados - sobretudo o WWW - para o plágio (total ou parcial de trabalhos académicos por parte dos alunos. Isto é, a localização, adoção e apresentação de ideias, teorias, hipóteses, resultados, textos, etc. alheios como próprios em qualquer trabalho académico. (Comas e Sureda, 2007, s. p).

O ciberplágio é assim uma prática de desonestidade intelectual, não apenas baseada na apropriação indevida de informação através do copy-paste, mas também na apropriação indevida de trabalhos já elaborados, ou na compra parcial ou total de trabalho através da internet. Como refere Comas e Sureda (2007), o plágio atual, sobretudo o académico, dispõe de novas formas, meios e facilidades. Por essa razão as repercussões e a profundidade são novas e parecem mais perigosas do que foram no passado. A problemática do plágio aparece com frequência abordada nas questões relativas a crianças e segurança na internet. Este facto revela, só por si, alguma tomada de consciência dos perigos de uma utilização inconsciente da informação na era digital e da necessidade de tomar medidas para alterar comportamentos.

A mudança de paradigma para aceder à informação pode ter contribuído para a extensão do fenómeno. Ponte (2010) alerta para o aumento de utilização da internet por crianças e jovens na realização de trabalhos escolares, sobretudo com o objetivo de plagiar. Segundo a mesma autora, as crianças vão à internet fazer pesquisa para o trabalho escolar e muitas vezes essa pesquisa é um plágio. Para a investigadora, muitas crianças pensam que fazer pesquisa é ir à internet, está aqui, corta, cola, imprime e já está, disse a investigadora, chamando a atenção para os efeitos negativos na qualidade do conhecimento que se adquire. ${ }^{2}$ Segundo Morais $(2008)^{3}$ a insensibilização para o plágio começa desde cedo, muitas vezes ainda no pré-escolar, por exemplo, na pesquisa de imagens para ilustrar trabalhos escolares. E acrescenta algo que é indiscutível: os

\footnotetext{
${ }^{2}$ Cristina Ponte in: http://expresso.sapo.pt/internet-jovens-confundem-pesquisa-com-plagio=f562506

${ }^{3}$ Tito Morais in: http://www.miudossegurosna.net/artigos/2008-05-16.html
} 
alunos estão cada vez mais, por vezes exclusivamente, dependentes da internet como única ferramenta de pesquisa. Esse facto, em si mesmo, não é o problema, e sim a educação e os hábitos de utilização que os alunos adquirem no uso das novas tecnologias; isso torna necessário que a escola reflita a respeito.

Segundo alguns investigadores, podem apontar-se vários comportamentos dos professores que concorrem para a prática do plágio por parte dos seus alunos: “... a leviana ou escassa supervisão dos trabalhos solicitados aos alunos; a fraca clareza das instruções dadas quando se solicitam os trabalhos; a descoordenação com os outros professores do curso; o tipo e número de trabalhos que se pedem aos alunos e a sua própria ingenuidade" (Sureda, Comas e Morey, 2009). A brecha digital entre alunos da era digital (nativos digitais) e pais e professores (imigrantes digitais) pode fazer com que estes não tenham plena consciência dos hábitos que os alunos desenvolveram, pois a internet no mundo escolar é vista como meio de aceder à informação para construir conhecimento. No mundo digital a capacidade de leitura e escrita tem vindo a alterar-se. Os textos do mundo digital, derivados de SMS, chats, fóruns, redes sociais ou WhatsApp, são de sintaxe simples, léxico redundante e onomatopeias expressivas que aligeiram a leitura e exigem um nível baixo de atenção e descodificação (Balano e Muñoz, 2015).

Sobre as razões de plagiar, identificamos na bibliografia várias justificações de recurso ao plágio, como a obtenção de prestígio e boas avaliações, a falta de tempo para fazer o trabalho, deixar andar e fazer na última hora e obtenção de prémios. Esta prática pode também estar associada ao desconhecimento ou falta de informação dos alunos sobre regras de elaboração de trabalhos e a uma consciência mais ou menos evidente da sua ilegalidade. Segundo Comas e Sureda (2007) citando Dordov (2002) podem identificar-se quatro razões que conduzem os alunos a esta situação:

1- Tentar obter melhores classificações e resultados académicos; 2- Preguiça e má gestão do tempo dedicado ao estudo e à elaboração dos trabalhos; 3Facilidade e comodidade de acesso a material via internet; 4- Desconhecimento das normas básicas a seguir para a elaboração de um trabalho académico (s. p.).

Desde os primeiros níveis de escolaridade que, com frequência, se solicitam trabalhos aos alunos (em grupo ou individuais), muitas vezes sem preocupação das regras de conceção. A maior parte das vezes, apenas é sugerido o tema. Muitos alunos poderão optar pelo mais fácil: colocam o tema num motor de busca (geralmente o Google), veem o que aparece, copiam, colam, imprimem e entregam o trabalho. Normalmente sem preocupação de verificar a credibilidade da informação e de selecionar o mais relevante. Muitos alunos "esquecem" de fazer referências bibliográficas ou de fazer citações mencionando a fonte e o autor. Trabalhar a informação recolhida, no sentido de a avaliar, fazer análises e sínteses, não é um processo fácil. Sem estas competências para refletir sobre a informação recolhida e 
construir o próprio discurso, enveredar pelo copiar e o colar será a lei cognitiva do menor esforço.

Para além das causas, um dos aspetos centrais na problemática do plágio é a forma de o combater. Se se persistir em continuar a fingir que a prática de plágio não existe, corremos o risco de os alunos terem cada vez mais dificuldade em expressar a sua forma de pensar, de interpretar, de investigar e de escrever um discurso coerente.

Para poder prevenir o fenómeno temos de conhecer as suas causas, a sua origem. Para tentar ir mais longe no aspeto da prevenção há que reconhecer que esses comportamentos têm uma causa multifatorial, que só podem ser evitados com políticas institucionais para melhorar as práticas de ensino, os ambientes e a avaliação da aprendizagem (Dias e Bastos, 2013). Pinto e Gerrero (2014) afirmam que "as respostas pedagógicas permanecem no tempo pois incidem sobre a raiz do problema. E, claramente é muito mais satisfatório educar que vigiar" (p. 23).

\section{Metodologia}

No âmbito da temática do nosso trabalho sobre a prática do ciberplágio em contexto escolar no ensino secundário, tivemos necessidade de elaborar um conjunto de objetivos que nos permitissem direcionar e orientar a investigação. Assim, pretendemos com este trabalho investigar os conhecimentos que os alunos possuem sobre o plágio, o nível de consciência, as suas práticas e as formas de o combater. Temos como meta alcançar os alvos do estudo a seguir listados, tendo em atenção que são objetivos do contexto em análise: verificar o nível de consciência dos alunos em relação à ilegalidade da prática de plágio; conhecer práticas de plágio dos estudantes do ensino secundário; identificar as causas e consequências do plágio no Ensino Secundário; identificar formas de combate ao plágio em ambiente escolar.

Para realizar a investigação seguimos a metodologia de estudo de caráter descritivo, procurando identificar e analisar alguns fatores ou variáveis relacionadas com o fenómeno em causa. Decidimos estudar o comportamento dos alunos de uma escola do distrito de Bragança (Norte de Portugal), por meio de um questionário on-line enviado a todos os alunos do Ensino Secundário da escola em estudo, além de entrevistas a quatro professores e análise documental de regulamentos internos da escola.

Os inquéritos por questionário em suporte digital foram enviados via internet e estiveram disponibilizados aos alunos durante cerca de três meses. O questionário era constituído por questões fechadas e uma questão aberta de opinião sobre o plágio, e visou obter informação sobre o nível de conhecimento dos alunos sobre o plágio, conhecer a difusão e o tipo de práticas, procurar causas, bem como recolher a opinião dos alunos sobre o plágio e formas de o combater. Para a análise das respostas dadas aos questionários e realização dos gráficos foi utilizada a folha de cálculo Excel. 


\section{Apresentação e análise dos resultados}

Neste estudo, o inquérito foi direcionado exclusivamente para os alunos do Ensino Secundário. Na escola pesquisada, o ensino engloba na sua totalidade 348 alunos, distribuídos pelos $10^{\circ}, 11^{\circ}$ e $12^{\circ}$ anos. Responderam ao questionário 148 alunos, 99 do sexo feminino e 49 do sexo masculino. 57,4\% dos alunos que responderam ao inquérito habitam na zona urbana e $42,6 \%$ habitam em zona rural. Quase todos os alunos possuem internet em casa $(97,3 \%)$ e $3,7 \%$ afirmam não a possuir. Dos alunos que responderam ao inquérito, $41,2 \%$ eram do $10^{\circ}$ ano, $36,5 \%$ eram do $11^{\circ}$ e $22,3 \%$ eram do $12^{\circ}$ ano.

Após a análise dos documentos internos da escola, nomeadamente o regulamento de avaliação, verificamos que não se aborda a problemática do plágio em qualquer dos documentos da escola. Isto pode demonstrar que a escola não se preocupa ainda com esta problemática. Uma análise dos documentos on-line das escolas da região mostra a mesma realidade.

Em primeiro lugar procuramos verificar o conhecimento dos alunos em relação à prática de plágio. Se observarmos o gráfico 1, relacionado com o facto de os alunos já terem ouvido falar em plágio académico, podemos constatar que $81,1 \%$ dos alunos deu uma resposta positiva. Em contrapartida, 18,9\% dos alunos nunca ouviram falar de plágio académico. Verificamos que a grande maioria já ouviu falar do assunto, contudo existe um número ainda considerável de alunos que nada sabem sobre plágio académico.

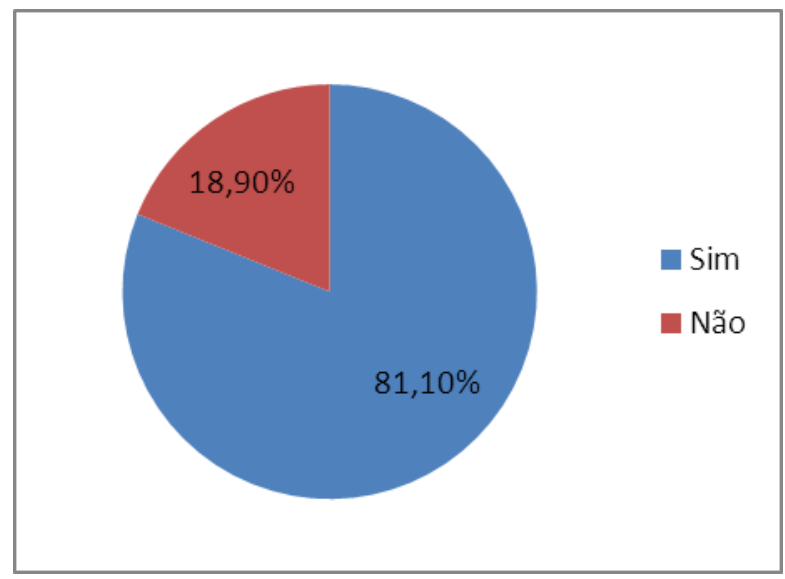

Gráfico 1. Ouvir falar em plágio académico.

Analisando o gráfico 2, é possível identificar o grau de conhecimento que os alunos consideram possuir relativamente ao plágio em contexto escolar. Então 10,8\% dos alunos consideram não estar informados, 18,9\% estão pouco informados, 44,6\% acham estar informados, 20,9\% consideram estar bem informados e 4,7\% julgam estar muito bem informados. Podemos reconhecer que alguns alunos se consideram informados sobre o plágio em contexto escolar, embora ainda haja uma preocupante percentagem de alunos que parece desconhecer o plágio académico. 


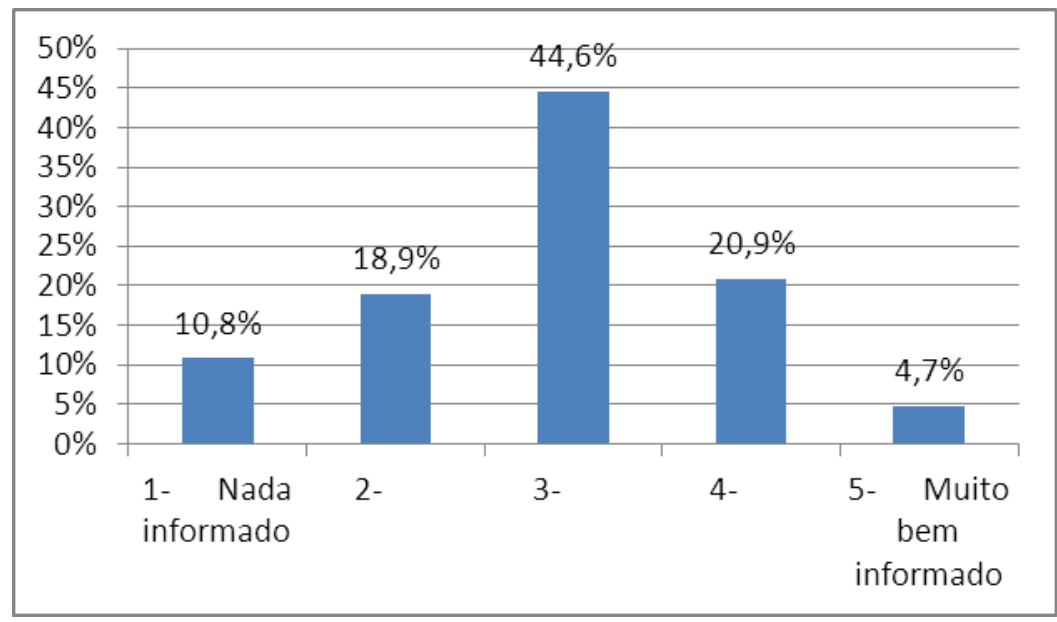

Gráfico 2. Informação sobre o plágio.

Na questão para identificar a definição mais completa de plágio constatamos que $75 \%$ dos alunos, ou seja, a maioria referiu que o plágio "É a utilização, por parte de alguém, de uma obra, ou parte dela, que apesar de ter sido realizada por outras pessoas, a assume como sua". Isso indica que a grande maioria dos alunos tinha conhecimento do conceito de plágio académico. Na questão aberta para expressar a sua opinião sobre o plágio surgem várias respostas que nos indicam que os alunos estão bem conscientes sobre esta prática. Há frases como "Não posso considerar uma boa atitude, mas muitas vezes é necessária, devido ao termos muitos trabalhos para fazer ao mesmo tempo" ou “Sei que esta prática não é muito correta, mas às vezes dá jeito!". Mas também existem alunos que reconhecem a necessidade de abordar essa temática na escola: "Devia haver mais informação nas escolas, e os professores deviam explicar aos alunos que praticam plágio, quais as razões para não o fazerem." São várias as opiniões que reconhecem esta necessidade. Apesar de muitos alunos se considerarem informados, ainda existe uma grande percentagem que considera possuir pouca informação. Esta afirmação pode ser corroborada pelos dados obtidos na pergunta sobre o conhecimento de software para a deteção de trabalhos plagiados: 58,1\% dos alunos dizem conhecer algum tipo de software antiplágio, enquanto $41,9 \%$ não conhece qualquer tipo de software para tal fim.

Relativamente aos dados apresentados pelo gráfico 3, que designa a frequência com que os alunos recorrem ao processo de copiar-colar, podemos averiguar que $16,2 \%$ dos alunos afirma nunca ter recorrido a esse processo, enquanto $32,4 \%$ o faz raramente e 31,8 o pratica por vezes. Esta prática é frequente para 16,9\% dos alunos. Apenas 2,7\% afirma que o faz sempre. 


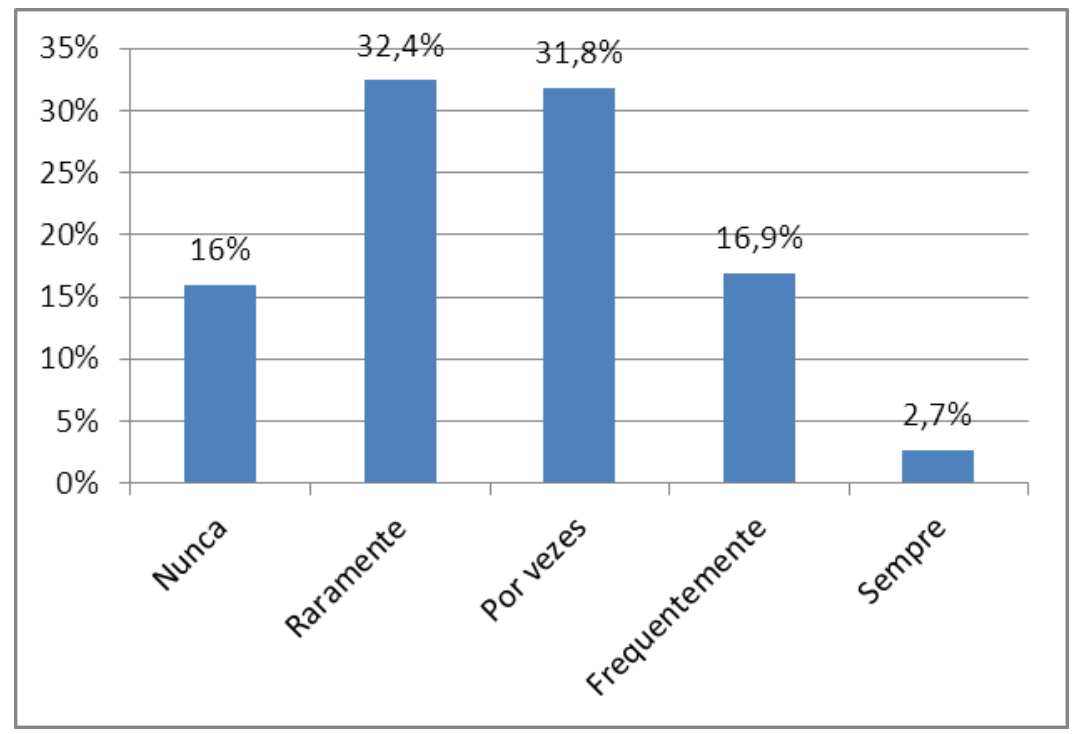

Gráfico 3. Frequência de utilização do processo copiar-colar na realização de trabalhos.

Em relação à frequência com que os alunos copiam trabalhos já feitos na internet, conforme o gráfico 4, apuramos que 51,4\% dos alunos nunca utilizaram essa prática. Já 31,1\% dos alunos raramente o fazem, enquanto $13,5 \%$ dos alunos costumam, por vezes, valer-se dessas cópias, $1,4 \%$ fá-lo frequentemente e $2,7 \%$ copiam sempre trabalhos já feitos na internet.

Verificamos que esta prática, apesar de ser evidente nestes alunos, não é tão expressiva como a prática do plágio através do processo copiar-colar.

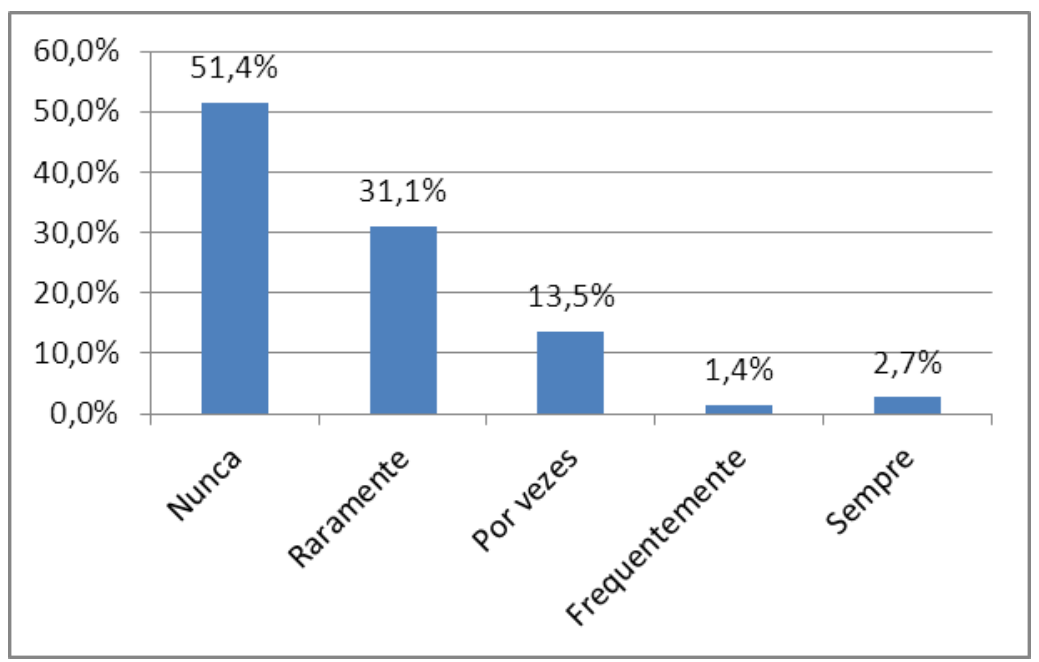

Gráfico 4. Frequência com que os alunos copiam trabalhos já feitos na internet

Em relação à frequência com que os alunos compram trabalhos feitos a partir da internet, verificamos que 95,3\% afirma nunca o ter feito e 2,7\% afirma que o faz raramente. A prática de compra de trabalhos através da internet, apesar de existir, é 
pouco expressiva, comparada com o processo de copiar-colar e com a cópia de trabalhos já feitos na internet.

Podemos também apurar que a área disciplinar em que os alunos recorrem mais à prática do plágio é a de Filosofia, com $47 \%$ dos alunos a afirmar que já recorreram a essa prática, seguida da área de Língua Portuguesa, com $31 \%$ de respostas positivas. Verifica-se também que $29 \%$ já recorreu a essa prática na área disciplinar de Educação Física. É curioso que nalgumas respostas de opinião alguns alunos afirmaram que nesta área é importante o plágio pois a disciplina "não conta para nada". Outras áreas de relevo são a Biologia (20\%), a Geologia (10\%), a Psicologia (9\%) e a História (7\%). Áreas onde é necessária a realização de cálculos (Matemática, Física e Química) bem como as línguas estrangeiras (Inglês e Francês) possuem uma expressão de plágio nula ou praticamente nula.

$\mathrm{Na}$ entrevista realizada aos professores, referiram que o plágio costuma acontecer com alguma frequência em relatórios de atividades, projetos finais de cursos profissionais, trabalhos completos ou apenas frases. Um professor mencionou que não acontece com muita frequência e que por norma os alunos apenas copiam frases e nunca trabalhos completos. Contudo, devemos estar conscientes de que copiar frases não deixa de ser plágio.

\begin{tabular}{|l|r|r|r|r|r|r|}
\hline \multicolumn{1}{|c|}{ Causas do plágio } & \multicolumn{1}{c|}{ Nada } & \multicolumn{1}{c|}{ Pouco } & \multicolumn{1}{c|}{ Algo } & \multicolumn{1}{c|}{ Bastante } & \multicolumn{1}{c|}{ Muito } & \multicolumn{1}{c|}{ Soma } \\
\hline $\begin{array}{l}\text { Pela facilidade que a internet } \\
\text { oferece para copiar } \\
\text { informação }\end{array}$ & 15,5 & 14,9 & 31,1 & 26,4 & 12,8 & 70,3 \\
\hline $\begin{array}{l}\text { Por falta de tempo para } \\
\text { escrever o trabalho }\end{array}$ & 7,4 & 27,7 & 35,1 & 20,3 & 9,5 & 64,9 \\
\hline $\begin{array}{l}\text { Porque a escola não informa } \\
\text { sobre o plágio }\end{array}$ & 17,6 & 25,7 & 29,7 & 16,2 & 10,8 & 56,7 \\
\hline $\begin{array}{l}\text { Porque costumo deixar os } \\
\text { trabalhos para a última hora }\end{array}$ & 15,5 & 30,4 & 29,1 & 17,6 & 7,4 & 54,1 \\
\hline $\begin{array}{l}\text { Porque os prazos para a } \\
\text { realização dos trabalhos são } \\
\text { curtos }\end{array}$ & 16,2 & 29,7 & 31,1 & 11,5 & 11,5 & 54,1 \\
\hline $\begin{array}{l}\text { Porque tudo o que existe na } \\
\text { internet pode ser copiado } \\
\text { livremente }\end{array}$ & 24,3 & 25 & 19,6 & 19,6 & 11,5 & 50,7 \\
\hline $\begin{array}{l}\text { Por dominar a internet e } \\
\text { tecnologias associadas }\end{array}$ & 15,5 & 35,8 & 27,7 & 13,5 & 7,4 & 48,6 \\
\hline $\begin{array}{l}\text { Porque se pode fazer melhor } \\
\text { trabalho com menos esforço }\end{array}$ & 17,6 & 36,5 & 24,3 & 14,2 & 7,4 & 45,9 \\
\hline $\begin{array}{l}\text { Porque os professores não } \\
\text { orientam na realização de } \\
\text { trabalhos }\end{array}$ & 20,9 & 24,5 & 29,1 & 13,5 & 2 & 44,6 \\
\hline $\begin{array}{l}\text { Porque nos trabalhos } \\
\text { copiados a classificação } \\
\text { costuma ser melhor }\end{array}$ & 28,4 & 31,8 & 22,3 & 11,5 & 6,1 & 39,9 \\
\hline $\begin{array}{l}\text { Falta de regras na elaboração } \\
\text { dos trabalhos }\end{array}$ & 20,9 & 41,9 & 27 & 6,8 & 3,4 & 37,2 \\
\hline
\end{tabular}




\begin{tabular}{|l|r|r|r|r|r|r|}
\hline \multicolumn{1}{|c|}{ Causas do plágio } & \multicolumn{1}{c|}{ Nada } & \multicolumn{1}{c|}{ Pouco } & \multicolumn{1}{c|}{ Algo } & \multicolumn{1}{c|}{ Bastante } & \multicolumn{1}{c|}{ Muito } & \multicolumn{1}{c|}{ Soma } \\
\hline $\begin{array}{l}\text { Por não ter capacidade de } \\
\text { escrita }\end{array}$ & 26.4 & 38,5 & 27 & 6,1 & 2 & 35,1 \\
\hline $\begin{array}{l}\text { Porque todos os colegas o } \\
\text { fazem de forma natural }\end{array}$ & 25,7 & 43,2 & 23,6 & 4,1 & 3,4 & 31,1 \\
\hline $\begin{array}{l}\text { Porque já o fazia no Ensino } \\
\text { Básico }\end{array}$ & 39,2 & 31,1 & 16,9 & 7,4 & 5,4 & 29,7 \\
\hline $\begin{array}{l}\text { Porque os professores não se } \\
\text { interessam pelo facto de o } \\
\text { trabalho estar copiado }\end{array}$ & 33,1 & 39,2 & 18,6 & 6,8 & 3,4 & 28,8 \\
\hline
\end{tabular}

Tabela 1. Causas do plágio

Em relação às causas do plágio, apresentamos na tabela 1 uma descrição de fatores que podem conduzir ao plágio, selecionados a partir da consulta bibliográfica sobre a temática. Os resultados das respostas estão apresentados em percentagens.

Verificamos que os alunos atribuem mais importância a uns fatores do que a outros. Se somarmos (coluna soma) as três últimas categorias de resposta da tabela 1 (Algo, Bastante e Muito), em todos os fatores e ordenarmos os fatores por ordem de importância, observamos que alguns possuem respostas superiores a 50\%, em áreas relacionadas com a internet e a facilidade de copiar e colar, bem como de fatores relacionados com o tempo, como o prazo dado para a realização dos trabalhos, o "deixar para a última hora". Esses aspetos remetem para a ausência de hábitos de trabalho por parte dos alunos. A falta de informação sobre o plágio, por parte da escola, revela-se também como um fator importante. Poderá significar que alguns alunos modificariam o hábito de recorrer ao plágio se a escola se preocupasse em informar a comunidade educativa sobre essa prática.

Os professores identificaram essencialmente três razões para a prática do plágio: a falta de preparação para realizar investigação, a abundância de material disponível na internet; e a possibilidade de o praticarem por desconhecimento do que significa plagiar.

Sobre as medidas para combater o plágio, apresentamos as respostas dos alunos na tabela 2 (apresentadas em percentagem de respostas). Verificamos, considerando o somatório das categorias 3, 4 e 5, que as medidas de caráter de consciencialização e debate do tema, a nível da comunidade escolar e também a um nível mais macro (Ministério da Educação), são bem acolhidas pelos alunos. As medidas relacionadas com a atuação pedagógica dos professores, no sentido de fornecer regras claras sobre a realização dos trabalhos, são também bem aceites.

\begin{tabular}{|l|r|r|r|r|r|r|}
\hline $\begin{array}{c}\text { Medidas para } \\
\text { combater o plágio }\end{array}$ & $\begin{array}{c}\text { 1 - Discordo } \\
\text { completamente }\end{array}$ & \multicolumn{1}{|c|}{$\mathbf{2}$} & \multicolumn{1}{c|}{$\mathbf{3}$} & \multicolumn{1}{c|}{$\mathbf{4}$} & $\begin{array}{c}\text { 5-Concordo } \\
\text { completamente }\end{array}$ & Soma \\
\hline $\begin{array}{l}\text { A escola deveria } \\
\text { consciencializar a } \\
\text { comunidade escolar }\end{array}$ & 4,7 & 4,1 & 27 & 20,9 & 43,2 & 91,1 \\
\hline $\begin{array}{l}\text { Os professores } \\
\text { deveriam fornecer }\end{array}$ & 4,1 & 7,4 & 22,3 & 27,7 & 38,5 & 88,5 \\
\hline
\end{tabular}




\begin{tabular}{|l|r|r|r|r|r|r|}
\hline \multicolumn{1}{|c|}{$\begin{array}{c}\text { Medidas para } \\
\text { combater o plágio }\end{array}$} & $\begin{array}{c}\text { 1-Discordo } \\
\text { completamente }\end{array}$ & \multicolumn{1}{c|}{$\mathbf{2}$} & \multicolumn{1}{c|}{$\mathbf{3}$} & $\mathbf{4}$ & $\begin{array}{c}\text { 5- Concordo } \\
\text { completamente }\end{array}$ & Soma \\
\hline $\begin{array}{l}\text { regras claras sobre a } \\
\text { realização de trabalhos }\end{array}$ & 5,4 & 8,1 & 31,8 & 19,6 & 35,1 & 86,5 \\
\hline $\begin{array}{l}\text { O Ministério da } \\
\text { Educação deveria } \\
\text { fazer com que o tema } \\
\text { fosse debatido nas } \\
\text { escolas }\end{array}$ & 11,5 & 8,1 & 32,4 & 20,9 & 27 & 80,3 \\
\hline $\begin{array}{l}\text { Os professores } \\
\text { deveriam acompanhar } \\
\text { a realização dos } \\
\text { trabalhos }\end{array}$ & 14,9 & 13,5 & 29,7 & 15,5 & 26,4 & 71,6 \\
\hline $\begin{array}{l}\text { Os trabalhos plagiados } \\
\text { deveriam ser anulados }\end{array}$ & 44,6 & 22,3 & 21,6 & 6,1 & 5,6 & 33,3 \\
\hline $\begin{array}{l}\text { Os alunos deveriam } \\
\text { chumbar na disciplina } \\
\text { onde cometem plágio }\end{array}$ & & & & & & \\
\hline
\end{tabular}

Tabela 2. Medidas para combater o plágio

As medidas menos recetivas por parte dos alunos são aquelas de caráter mais punitivo, como reprovar na disciplina onde o trabalho fosse plagiado. A medida de anular os trabalhos plagiados também é bem acolhida, apesar de não ser tanto como as medidas de sensibilização e de atuação pedagógica dos professores na realização dos trabalhos.

A ideia de penalização encontra-se também bastante evidente nas respostas dos alunos na questão aberta sobre a opinião do plágio. Mencionam também que é injusto para quem se esforça, e que quem o pratica obtém resultados sem qualquer tipo de esforço.

Através das entrevistas dos professores e reportando às medidas para combater o plágio, todos eles referiram que será cada vez mais necessário adotar medidas de combate ao plágio, sugerindo ideias como: Proibir o plágio na elaboração de trabalhos; punir esses alunos; adotar guias de literacia existentes na biblioteca; adotar estratégias e medidas para lhes explicar o que é o plágio. A apresentação dos trabalhos de forma oral, na aula, é também uma forma que os professores entrevistados defendem, bem como alguns alunos nas respostas abertas, pois os obriga a estruturar o trabalho para o poder apresentar e defender, o que implica envolvimento na aprendizagem.

\section{Conclusão}

É hoje impensável negar o acesso à internet aos alunos na realização dos trabalhos académicos, mas deve ser repensado todo o contexto pedagógico que suporta ou permite a existência da prática do plágio. Se se continuar com a cabeça debaixo da areia, sem preocupação sobre este fenómeno emergente, não estaremos, certamente, a contribuir para aumentar o nível de literacia, e a estimular a capacidade mental e o 
desenvolvimento da capacidade de pensar de forma estruturada. Este comportamento é bem patente no nosso estudo. Na escola em causa, a nível do Ensino Secundário, apesar de não podermos generalizar, podemos afirmar que a maioria dos alunos tem consciência desta prática e opta por uma definição correta de plágio. A grande maioria também o pratica com maior ou menor frequência. Essa prática assenta mais no processo de copiar-colar utilizando informação da internet do que no plágio de trabalhos já elaborados e disponibilizados na rede. Com menor expressão ainda se encontra a compra de trabalhos através da internet. As áreas disciplinares mais plagiadas parecem ser aquelas onde é exigida maior capacidade de escrita, como a filosofia e a língua portuguesa. As menos plagiadas foram as disciplinas onde é necessária a realização de cálculos, como a matemática, a física e a química, bem como as disciplinas de língua estrangeira.

Sobre as causas do plágio verificamos que existe um conjunto de fatores mais importante que podem induzir ao plágio. Um fator pode ser descrito como a facilidade de aceder à informação da internet ao que podemos associar a ideia de que na internet tudo pode ser copiado. Outro fator importante relaciona-se com a organização do tempo para a realização dos trabalhos escolares (falta de tempo, tempos curtos para a realização e por deixar para a última hora). Ainda, um outro fator que nos parece importante relaciona-se com a falta de esclarecimento sobre a prática do plágio. Deduzimos que, se a escola informasse mais os alunos sobre a temática, o comportamento dos alunos poderia alterar-se.

Sobre as medidas para combater o "flagelo" destacam-se as de sensibilização por parte da escola e também do Ministério da Educação. As escolas deveriam começar a preocupar-se com esse alerta e, a um nível mais abrangente, o Ministério da tutela poderia tomar medidas, tal como o fez para a segurança na internet, criando uma semana dedicada a essa temática.

A um nível micro são também consideradas importantes as medidas que os professores podem tomar, no sentido de fornecerem regras para a realização de trabalhos, acompanharem a sua realização e propor a sua apresentação. O problema parece não ser simples e, muito provavelmente, a responsabilidade da solução poderá não depender apenas dos professores. É certo que as práticas de realização de trabalhos necessitarão de ser alteradas, nomeadamente no tipo de trabalhos a realizar, nas regras de realização e no acompanhamento por parte dos docentes. Isso poderá obrigar a repensar o desenho curricular e as estratégias de aprendizagem. O plágio introduz variáveis novas na prática educativa e, nesse contexto, mais do que solicitar respostas isoladas dos professores, a solução deve ser encontrada mais em contexto de escola ou mesmo numa reação de todo o sistema educativo.

Medidas muito severas ou punitivas são menos aceites pelos alunos. A maioria concorda com a anulação dos trabalhos plagiados, mas não concorda com a reprovação na disciplina onde se verificou o plágio. Esse aspeto vai ao encontro às propostas de 
Pinto e Gerrero (2014), quando referem que as respostas pedagógicas permanecem no tempo incidindo sobre a raiz do problema.

As crianças de hoje vivem imersas na internet e nas tecnologias associadas. A escola tem procurado fazer com que os alunos aprendam com as tecnologias, ou seja, aprender com os meios, procurando a informação disponibilizada. Contudo, a escola tem estado bastante afastada da faceta de educar para os meios, ou seja, para a utilização consciente das tecnologias de informação e comunicação (TIC). A utilização destas requer regras, valores e uma forte dimensão ética (Meirinhos, 2013). Essa faceta tem estado completamente ausente da educação dos nativos digitais. Não basta educar com os meios, é necessário educar para os meios. Com a utilização menos consciente das tecnologias o aluno prejudica a si mesmo, uma vez que deixa de desenvolver competências de escrita e a capacidade de fazer análises e sínteses, necessárias para o pensamento lógico e estruturado. A capacidade de ler, analisar e sintetizar ideias de vários autores para depois articular esses conteúdos num novo texto próprio é uma habilidade importante para o desenvolvimento da competência crítica e deveria ser valorizada no meio escolar.

Em síntese, com este trabalho pretendemos transformar uma problemática latente e torná-la mais visível e consciente para a criação de condições de ação. Ao contrário de muitos outros dilemas que a escola enfrenta, esse não segue a mesma lógica. São normalmente os problemas sociais emergentes que são transferidos para a escola e solicitada a sua resolução. No caso do ciberplágio é um problema que surge em contexto de aprendizagem escolar e coloca em causa os valores da aprendizagem. Esse flagelo educacional, se não for resolvido, irá acentuar-se cada vez mais e poderá transformar-se num problema social.

\section{Referências}

Balano, I. e Muñoz, I. (2014). Competencia lecto-escritora y plagio: los desafíos de la era digital. In R. Comas e J. Sureda (Coord.) El plagio académico en educación secundária: características del fenómeno y formas de intervención. (pp. 8-27). Palma: EIC.

Comas, R. e Sureda, J. (2007). Ciber-Plagio Académico. Una aproximación al estado de los conocimientos. Revista TEXTOS de la CiberSociedad, 10.

Comas, R., Sureda J. e Urbina S. (2005). The 'Copy and Paste' Generation: Plagiarism Amongst Students, a Review of Existing Literature. The International Journal of Learning. The International Journal of Learning. 12, 161-168.

Dias, P. e Bastos, A. (2013). Plagiarism and learning: Contributions from research to educational practice. In P. Dias e A. Bastos (Org.) Plagiarism, Phenomenon in Europe: research contributes to prevention. (pp. 15-27). Faculdade de Filosofia: Braga.

Meirinhos, M. (2013). Teachers and ICT skills: towards a new digital literacy. In P. Dias, e A. Bastos (Org.) Plagiarism, Phenomenon in Europe: research contributes to prevention. (pp. 28-39). Faculdade de Filosofia: Braga. 
Pinto, M. e Guerrero, D. (2014). La importancia de las competencias informacionales para afrontar el plagio académico: estrategias para la alfabetización informacional del alumnado de secundaria y bachillerato. In R. Comas e J. Sureda (Coord.) El plagio académico en educación secundária: características del fenómeno y formas de intervención. (pp. 28-36). Palma: EIC.

Prensky, M. (2001). Digital Natives, Digital Immigrants. On the Horizon. 9 (5). Recuperado em 18 de maio de 2012, de http://www.marcprensky.com/writing/Prensky\%20-

\%20Digital\%20Natives,\%20Digital\%20Immigrants\%20-\%20Part1.pdf

Sureda, J., Comas, R. e Morey, M. (2009). Las causas del plagio académico entre el alunado universitário según el professorado. Revista Iberoamericana de Educación, 50, 197-220.

Sureda, J., Comas, R. e Oliver, M. (2015). Plagio académico entre alumnado de secundaria y bachillerato: Diferencias en cuanto al género y la procrastinación. Comunicar. XXII (5)103-111.

Tapscott, D. (1997). Growing Up Digital: The Rise of the Net Generation. Mcgraw-Hill.

Underwood, J. (2013). Academic dishonesty: A fuss about nothing? InP.Dias eA. Bastos (Org.) Plagiarism, Phenomenon in Europe: research contributes to prevention. Faculdade de Filosofia: Braga.

Data de recepção: 05/07/2015

Data de revisão: 01/11/2015

Data do aceite: 23/11/2015 